\title{
PENGARUH PENYALAHGUNAAN TEKNOLOGI INFORMASI DAN \\ INTEGRITAS MAHASISWA TERHADAP PERILAKU \\ KECURANGAN AKADEMIK MAHASISWA \\ AKUNTANSI SEBAGAI CALON \\ AKUNTAN \\ (Studi Kasus Mahasiswa Universitas Sulawesi Barat Prodi Akuntansi)
}

Technology Information And Integrity Of Students On Academic Disease Accounting Students As Accounting Candidates. Study On Accounting studenst at the University of west Celebes.

\author{
Sitti Hadijah \\ Email: hadijah@unsulbar.ac.id \\ Prodi Akuntansi Fakultas Ekonomi unsulbar \\ J. Prof. Baharuddin Lopa, S Talumung Majene Sulawesi Barat \\ Jamaluddin \\ Email: Jamaladitia@gmail.com \\ Prodi Akuntansi Fakultas Ekonomi unsulbar
}

\begin{abstract}
ABSTRAK
Tujuan penelitian ini adalah untuk mengetahui pengaruh penyalahgunaan teknologi informasi dan Integritas Mahasiswa terhadap perilaku kecurangan akademik mahasiswa akuntansi sebagai calon akuntan, pada Mahasiswa Universitas Sulawesi Barat. Adapun penelitian adalah kuantitatif asosiatif. Dengan Populasi berjumlah 219 dan sampel 36 mahasiswa angkatan 2015 dan 2017. Teknik pengambilan sampel yang digunakan adalah stratified sampling dengan menggunakan teknik pengumpulan data berupa angket dengan instrumen meliputi uji validitas dan uji reliabilitas. Uji prasyarat meliputi uji normalitas dan uji linearitas, serta uji asumsi klasik meliputi uji mutikolinearitas dan uji heteroskedastisitas. Analisis data menggunakan analisis regresi ganda. Hasil penelitian ditunjukkan dengan koefisien Teknologi Informasi sebesar 0,411 dengan nilai signifikan variabel lebih kecil dari 0,05 yaitu sebesar 0,001. Integritas Mahasiswa sebesar -0,328 dengan nilai signifikan variabel Integritas Mahasiswa sebesar 0,05 yaitu sebesar 0,000. Pengaruh Kecurangan Akademik Mahasiswa Akuntansi ditunjukkan dengan nilai $\mathrm{F}$ hitung sebesar 21,583 dengan tingkat signifikan lebih kecil dari 0,05 yaitu sebesar 0,000 .

Kata Kunci: Penyalahgunaan Teknologi Informasi, Integritas Mahasiswa, Perilaku Kecurangan Akademik Mahasiswa.

\section{ABSTRACT}

The purpose of this study is to study the discussion of information technology and student integrity towards the academic cheating of accounting students as prospective accountants, at University of West Sulawesi Students. Associative quantitative research. With a population increase of 219 and a sample
\end{abstract}


of 36 students from 2015 and 2017. The sampling technique used was stratified sampling using a data collection technique in the form of a questionnaire with instruments that used validity and reliability tests. Test for normality and linearity test, as well as classicity test for multicollinearity test and heteroscedasticity test. Data analysis uses multiple regression analysis. The results of the study with the coefficient of Information Technology of 0.411 with a significant variable value smaller than 0.05 that is equal to 0.001. Student Integrity of $-0,328$ with a significant variable value of Student Integrity of 0.05 which is equal to 0,000. The Influence of Academic Fraud on Accounting Students assesses with a calculated $F$ value of 21.583 with a significantly smaller level of 0.05 which is equal to 0,000.

Keywords: Broadcasting Information Technology, Student Integrity, Student Academic Cheating Behavior.

\section{PENDAHULUAN}

Pendidikan merupakan suatu metode untuk mengembangkan keterampilan, kebiasaan dan sikap-sikap yang diharapkan dapat membuat seseorang menjadi lebih baik. Menurut Kamus Besar Bahasa Indonesia (KBBI) Pendidikan adalah proses-proses pengubahan sikap dan tata laku seseorang atau kelompok orang dalam usaha mendewasakan diri melalui upaya pengajaran, dan pelatihan, proses, cara, dan pembuatan mendidik.

Kecurangan akademik (academic dishonesty) merupakan berbagai bentuk perilaku yang mendatangkan keuntungan bagi mahasiswa secara tidak jujur termasuk di dalamnya menyontek pada saat ujian demi mendapatkan nilai yang diinginkan, menitip absen saat mereka berhalangan hadir agar persentase kehadiran penuh, mengcopy paste tugas teman, melakukan suap kepada Dosen dan masih banyak lagi kecurangan lainnya yang mereka perbuat. Ketika mahasiswa akuntansi seringkali melakukan tindak kecurangan akademik, maka mahasiswa tersebut tidak lagi menjadi seorang calon akuntan yang sesungguhnya.

Kegiatan akuntansi tidak terlepas dari seorang akuntan (ahli, gelar/ profesi) dan baik tidaknya suatu laporan keuangan ditentukan oleh banyak faktor, salah satunya yaitu akuntan (ahli, gelar/ profesi) karena akuntan yang nantinya akan membuat laporan keuangan dari proses akuntansi tersebut. Akuntan (ahli, gelar/ profesi) harus mempunyai tingkat kejujuran yang tinggi agar laporan keuangan sesuai dengan keadaan yang sebenarnya. Demikian juga dengan mahasiswa akuntansi harus mempunyai kejujuran yang tinggi pula karena mahasiswa akuntansi merupakan calon akuntan yang nantinya akan membuat laporan keuangan.

Kecurangan-kecurangan yang dilakukan oleh mahasiswa disebabkan oleh beberapa faktor antara lain faktor internal (motivasi belajar dan integritas mahasiswa) dan faktor eksternal (teknologi informasi). Perkembangan teknologi yang maju semakin pesat menjadikan berbagai kemudahan dapat dicapai dan mencari informasi menjadi lebih mudah, akan tetapi kemudahan itu sering sekali disalahgunakan oleh mahasiswa terutama di saat melakukan ujian dan kecurangan dapat dengan mudah dilakukan oleh semua kalangan. Adanya sosial media yang 
dapat diakses dengan mudah oleh mahasiswa merupakan faktor terpenting yang dapat memicu adanya kecurangan.

Kecurangan yang dilakukan mahasiswa juga dipengaruhi oleh integritas mahasiswa itu sendiri. Integritas yang dimiliki oleh mahasiswa akan menentukan apakah mahasiswa memiliki dorongan untuk melakukan kecurangan atau tidak. Integritas tersebut berkaitan dengan moralitas mahasiswa, ketaatan mahasiswa terhadap aturan akuntansi, latar belakang mahasiswa dan lain-lain. Integritas mahasiswa tersebut dapat menjelaskan kemungkinan mahasiswa mengambil keputusan-keputusan yang bersifat kurang etis atau bahkan melanggar hukum.

Berdasarkan pernyataan tersebut diatas perlu ditingkatkan motivasi belajar dan integritas mahasiswa, Penggunaan teknologi informasi harus dilakukan sesuai dengan perilaku positif, serta semua calon akuntan (ahli, gelar/ profesi) harus memenuhi standar kode etik yang berlaku dalam melaksanakan tanggung jawabnya dan menujukkan komitmen atas profesionalisme. Hal itulah yang melatar belakangi Penulis mengangkat judul "Pengaruh Penyalahgunaan Teknologi Informasi dan Integritas Mahasiswa terhadap Perilaku Kecurangan Akademik Mahasiswa Akuntansi sebagai Calon Akuntan (Studi Pada Mahasiswa Akuntansi Universitas Sulawesi Barat)".

\section{METODE PENELITIAN}

Penelitian merupakan kuantitatif asosiatif. Penelitian kuantitatif asosiatif adalah penelitian yang bertujuan untuk mengetahui hubungan dua variabel atau lebih (Sugiyono 2013 : 339 ). Penelitian ini bertujuan untuk mengetahui pengaruh penyalahgunaan teknologi informasi $\left(\mathrm{X}_{1}\right)$, integritas mahasiswa $\left(\mathrm{X}_{2}\right)$ terhadap perilaku kecurangan akademik yang dilakukan mahasiswa akuntansi (Y).

\section{Lokasi dan Waktu Penelitian}

Penelitian ini dilakukan di Universitas Sulawesi Barat khususnya Mahasiswa Akuntansi Fakultas Eknomi. Waktu penelitian mulai bulan Juli 2019.

\section{Populasi dan Sampel}

a. Populasi , Populasi adalah keseluruhan objek yang dapat terdiri dari manusis, benda-benda, hewan, tumbuh-tumbuhan, gejala, nilai, tes, ataupun peristiwa yang memilki karakteristik tertentu dalam suatu penelitian jadi, populasi dalam peneltian ini adalah Mahasiswa Universitas Sulawesi Barat Fakultas Ekonomi Prodi akuntansi.

b. Sampel, Sampel adalah bagian atau jumlah dan karakteritik yang dimiliki oleh populasi tersebut (Sugiyono 2017:118). Bila populasi besar, dan peneliti tidak mungkin semua yang ada pada populasi, misalnya karena keterbatasan dana, tenaga dan waktu, maka peneliti dapat menggunakan sampel yang diambil dari populasi itu.

c. Teknik Pengambilan Sampel,Teknik pengambilan sampel adalah probability sampling dengan menggunaka proportionate stratified random sampling. proportionate stratified random sampling adalah teknik yang digunakan bila populasi mempunyai anggota/unsur yang tidak homogen dan berstrata secara proporsional (Sugiyono, 2017:120). 


\section{Jenis dan Sumber data}

Jenis Sumber Data yang digunakan adalah Sumber Data Primer. Data primer mengacu pada informasi yang diperoleh langsung oleh peneliti terkait dengan variabel ketertarikan untuk tujuan tertentu dari studi (Uma Sekaran, 2017 : 130).

\section{Metode Pengumpulan Data}

a. Kuesioner/ Angket Kuesioner/ Angket merupakan teknik pengumpulan data yang dilakukan dengan cara memberikan seperangkat pertanyaan atau pernyataan tertulis kepada responden untuk dijawabnya.

b. Observasi, Observasi sebagai teknik pengumpulan data yang mempunyai ciri yang spesifik bila dibandingkan dengan metode yang lain (Sugiyono, 2017:203)

\section{Teknik Analisis Data}

a. Pengujian hipotesis secara parsial (Uji T)

Uji hipotesis secara parsial digunakan untuk mengetahui pengaruh dari masing-masing variabel bebas terhadap variabel terikat. Uji ini dilakukan dengan membandingkan nilai $\mathrm{T}$ hitung dengan nilai $\mathrm{T}$ tabel. Nilai $\mathrm{T}$ hitung dapat dilihat daari hasil pengelohan data bagian coenfficionts dengan tingkat signifikan $5 \%$ dengan uji $\mathrm{T}$, nilai $\mathrm{T}$ hitung akan dibandingkan dengan nilai $\mathrm{T}$ tabel dengan kesatuan sebagai berikut :

Jika t hitung $>\mathrm{t}$ tabel, maka $\mathrm{H}_{0}$ ditolak, $\mathrm{H}_{1}$ diterima.

Jika thitung $<\mathrm{t}$ tabel, maka $\mathrm{H}_{0}$ diterima, $\mathrm{H}_{1}$ tolak

b. Pengujian hipotesis secara simultan (Uji F)

Uji $\mathrm{F}$ digunakan untuk menguji signifikansi pengaruh variabel bebas secara serentak terhadap variabel terikat. Uji dilakukan dengna langkah membandingkan nilai dari F hitung dengan F tabel. Nilai F hitung Dapat dilihat dari hasil pengelolahan data bagian ANOVA. Taraf signifikan yang digunakan yaitu $\alpha=0,05$. Selanjutnya hasil hipotesis $F$ hitung dibandingkan dengan tabel dengan ketentuan sebagai berikut :

Kriteria pengambilan kesimpulannya sebagai berikut :

1. Jika nilai $\mathrm{F}$ hitung $>\mathrm{F}$ tabel, maka hipotesis alternatif (Ha) didukung yaitu variabel independen secara simultan berpengaruh secara signifikan terhadap variabel dependen.

2. Jika nilai $\mathrm{F}$ hitung $<\mathrm{F}$ tabel, maka hipotesis alternatif (Ha) ditolak yaitu variabel independen secara simultan tidak berpengaruh secara signifikan terhadap variabel dependen.

\section{c. Koefisien Determinasi}

Koefesien determinasi $\left(R^{2}\right)$ pada intinya mengukur seberapa jauh kemampuan model dalam menerangkan variasi variabel dependen. Nilai koefisien determinasi adalah nol dan satu. Nilai $R^{2}$ yang kecil berarti kemampuan variabel dependen amat terbatas. Nilai yang mendekati satu berarti variabel-variabel independen memberikan hampir semua informasi yang dibutuhkan untuk memprediksi variasi 
variabel dependen.

\section{HASIL DAN PEMBAHASAN}

Tabel 4.1 Hasil Uji Reliabilitas seluruh instrument

\begin{tabular}{ccc}
\hline Jumlah Item & Cronbach's Alpha & Keterangan \\
\hline 32 & 0,799 & Reliabel \\
\hline
\end{tabular}

Sumber : Data Primer, diolah pada tahun 2019

Berdasarkan Tabel di atas, semua variabel yang diuji dinyatakan reliabel karena memiliki Cronbach's Alpha atau koefisien alpha yang lebih besar dari 0,60 .

Tabel 4.2 Uji Normalitas One Sampel K-S One-Sample Kolmogorov-Smirnov Test

\begin{tabular}{llr}
\hline & & $\begin{array}{c}\text { Unstandardized } \\
\text { Residual }\end{array}$ \\
\hline $\mathrm{N}$ & & 36 \\
Normal & Mean & .0000000 \\
Parameters $^{\mathrm{a},}$ & Std. Deviation & 4.08358802 \\
$\mathrm{~b}$ & Absolute & .110 \\
Most & Positive & .075 \\
Extreme & Negative & -.110 \\
Differences & .662 \\
Kolmogorov-Smirnov Z & .773 \\
Asymp. Sig. (2-tailed)
\end{tabular}

a. Test distribution is Normal.

b. Calculated from data.

Sumber : Data Primer, diolah pada tahun 2019

Berdasarkan Tabel di atas, dapat dijelaskan bahwa besarnya nilai One Sample Kolmogorov-Smirnov $(K-S)$ adalah 0,662 dan nilai Asymp.Sig adalah $0,773(>0,05)$. Jadi, dapat disimpulkan bahwa data penelitian memenuhi asumsi normalitas.

Tabel 4.3 Hasil Multikolinearitas

\begin{tabular}{cccc}
\hline Ariabel & Tolerance & VIF & Kesimpulan \\
\hline $\begin{array}{c}\text { Penyalahguanaan } \\
\text { Teknologi Informasi }\end{array}$ & 0,951 & 1,063 & $\begin{array}{c}\text { Tidak terjadi } \\
\text { multikolineritas }\end{array}$ \\
\hline $\begin{array}{c}\text { Integritas } \\
\text { Mahasiswa }\end{array}$ & 0,951 & 1,063 & $\begin{array}{c}\text { Tidak terjadi } \\
\text { multikolineritas }\end{array}$ \\
\hline
\end{tabular}

Sumber : Data Primer, diolah pada tahun 2019

Berdasarkan Tabel di atas, dapat diketahui bahwa nilai Tolerance masingmasing variabel Teknologi Informasi dan Integritas Mahasiswa memiliki nilai 
Tolerance $>0,10$ dan nilai VIF $<10$, maka dapat disimpulkan bahwa tidak terjadi multikolinearitas pada masing-masing variabel Teknologi Informasi dan Integritas Mahasiswa.

Tabel 4.4 Hasil Heteroskedastisitas

\begin{tabular}{lccl}
\hline \multicolumn{1}{c}{ Variabel } & A & Sig. & \multicolumn{1}{c}{ Keterangan } \\
\hline $\begin{array}{l}\text { Penyalahguanaan } \\
\text { Teknologi } \\
\text { Informasi }\end{array}$ & 0,05 & 0,267 & $\begin{array}{l}\text { Tidak terjadi } \\
\text { heteroskedastisitas }\end{array}$ \\
\hline Integritas Mahasiswa & 0,05 & 0,703 & $\begin{array}{l}\text { Tidak terjadi } \\
\text { heteroskedastisitas }\end{array}$ \\
\hline
\end{tabular}

Sumber : Data Primer, diolah pada tahun 2019

Dari tabel diatas dapat diketahui bahwa nilai signifikansi atau sig. (2tailed) variabel Teknologi Informasi $\left(X_{1}\right)$ sebesar $0,267>0,05$ dan variabel Integritas Mahasiswa $\left(\mathrm{X}_{2}\right)$ sebesar 0,703>0,05 sehingga dapat disimpulkan bahwa tidak terdapat masalah atau gejala heteroskedastisitas.

\begin{tabular}{|c|c|c|c|c|c|c|}
\hline \multicolumn{7}{|c|}{$\begin{array}{c}\text { Tabel 1. hasil uji T } \\
\text { Coefficients }^{\mathrm{a}}\end{array}$} \\
\hline \multirow{2}{*}{\multicolumn{2}{|c|}{ Model }} & \multicolumn{2}{|c|}{ Unstandardized Coefficients } & \multirow{2}{*}{$\begin{array}{l}\text { Standardized } \\
\text { Coefficients } \\
\text { Beta }\end{array}$} & \multirow[t]{2}{*}{$\mathrm{T}$} & \multirow[t]{2}{*}{ Sig. } \\
\hline & & B & Std. Error & & & \\
\hline & (Constant) & 27,098 & 3,963 & & 6,837 & ,000 \\
\hline & $\begin{array}{l}\text { Teknologi } \\
\text { Informasi }\end{array}$ & ,411 &, 119 & ,268 & 3,470 & 001 \\
\hline & $\begin{array}{l}\text { Integritas } \\
\text { Mahasiswa }\end{array}$ &,- 328 &, 072 &,- 354 & -4.582 &, 000 \\
\hline
\end{tabular}

Sumber : Data Primer, diolah pada tahun 2019

Hasil uji t diatas menunjukan bahwa pada variabel Teknologi Informasi $\left(X_{1}\right)$ diperoleh $t$ hitung sebesar 3,470 sedangkan nilai t tabel dengan taraf nyata $(\alpha)$ sebesar 0,05 (5\%) serta $\mathrm{df}=\mathrm{n}-\mathrm{k}-1(36-2-1)=33$ adalah sebesar 2,03452, jadi dapat di simpulkan bahwa $\mathrm{H}_{1}$ Diterimah karena nilai $\mathrm{t}$ hitung $>\mathrm{t}$ tabel serta nilai signifikan $\mathrm{X}_{1}$ sebesar $0,001<0,05$. jadi dapat di simpulkan bahwa Teknologi Informasi berpengaruh positif signifikan secara parsial terhadap Kecurangan Akademik (Y).

Hasil uji t pada variabel Integritas Mahasiswa $\left(\mathrm{X}_{2}\right)$ seperti pada tabel 4.13 diperolah $t$ hitung sebesar $-4,582$ sedangkan nilai t tabel sebesar 2,03452, jadi dapat di simpulkan bahwa $\mathrm{H}_{2}$ ditolak karena nilai $\mathrm{t}$ hitung $<\mathrm{t}$ tabel serta nilai signifikan $\mathrm{X}_{2}$ sebesar 0,000 karena nilai $\mathrm{T}$ Sig > 0,05. Jadi dapat di simpulkan bahwa Integritas Mahasiswa berpengaruh negatif signifikan secara parsial terhadap Kecurangan Akademik desa (Y). 
Tabel 4.14 Hasil Uji Statistik F

ANOVA $^{\mathrm{a}}$

\begin{tabular}{llcrrrr}
\hline Model & & $\begin{array}{l}\text { Sum of } \\
\text { Squares }\end{array}$ & Df & $\begin{array}{l}\text { Mean } \\
\text { Square }\end{array}$ & F & Sig. \\
\hline \multirow{2}{*}{1} & Regression & 511,457 & 2 & 255,729 & 21,583 &, $000^{\mathrm{b}}$ \\
\cline { 2 - 7 } & Residual & 1599,535 & 33 & 48,470 & & \\
\cline { 2 - 7 } & Total & 2110,993 & 35 & & & \\
\hline
\end{tabular}

a. Dependent Variable: Kecurangan Akademik

b. Predictors: (Constant), Teknologi Informasi, Integritas Mahasiswa

Sumber : Output SPSS 21, data diolah, 2019

Berdasarkan tabel di atas, hasil uji $\mathrm{F}$ menyatakan bahwa nilai $\mathrm{F}_{\text {hitung }}$ sebesar 21,583 dan $F_{\text {tabel }}$ hitung untuk tarif nyata sebesar 5\% df=k:n-k $(2: 36-2)=(2: 34)$ sebesar 3,28 dengan kata lain $F_{\text {hitung }}>F_{\text {tabel }}$ dan nilai signifikan sebesar 0,000, sehingga dapat disimpulkan bahwa $\mathrm{H}_{3}$ diterimah. Maka dapat di simpulkan bahwa secara simultan Teknologi Informasi (X1) dan Integritas Mahasiswa (X2) signifikan mempengaruhi Kecurangan Akademik (Y).

Tabel 4.15 Tabel Koefisien Determinasi Model Summary

\begin{tabular}{lcccr}
\hline Model & $\mathrm{R}$ & $\mathrm{R}$ Square & $\begin{array}{c}\text { Adjusted R } \\
\text { Square }\end{array}$ & $\begin{array}{c}\text { Std. Error of } \\
\text { the Estimate }\end{array}$ \\
\hline 1 &, $492^{\mathrm{a}}$ &, 242 &, 231 & 3,442 \\
\hline a. Predictors: (Constant), Transparansi, Akuntabilitas \\
Sumber: Output SPSS 21, data primer diolah pada tahun 2019 \\
Sumber: Output SPSS 21, data primer diolah pada tahun 2019
\end{tabular}

Pada tabel koefisien determinasi diatas dapat dilihat nilai Adjust R Square $\left(\mathrm{R}^{2}\right)$ adalah 0,242 . Hasil perhitungan statistik ini berarti bahwa kemampuan variabel independen dalam menerangkan variasi perubahan variabel dependen sebesar 24,2\%, sedangkan sisanya sebesar 75,8\% (100\% - 24,2\%) diterangkan oleh faktor-faktor lain di luar variabel yang diteliti.

Adapun faktor-faktor lain yang mempengaruhi variabel kecurangan akademik (Nursalam dan Munirah, 2013 : 137) anatara lain :

1. Individu, tujuan belajar dan tekanan orang tua

2. Lingkungan

3. Situasional

4. Jumlah materi dan perceived be-havioral control

5. Organisasi dan situasi

6. Psikososial.

\section{Pembahasan}

Penelitian ini bertujuan untuk menguji pengaruh Penyalahgunaan Teknologi Informasi $\left(\mathrm{X}_{1}\right)$ dan Integritas Mahasiswa $\left(\mathrm{X}_{2}\right)$ terhadap Perilaku 
Kecurangan Akademik Mahasiswa Akuntansi sebagai Calon Akuntan (Y). Berdasarkan hasil analisis, maka pembahasan tentang hasil penelitian adalah sebagai berikut:

Pengaruh Penyalahgunaan Teknologi Informasi terhadap Perilaku Kecurangan Akademik Mahasiswa Akuntansi sebagai Calon Akuntan.

Hasil uji hipotesis 1 menggunakan SPSS v.21 diketahui bahwa nilai koefisien regresi Teknologi Informasi $\left(\mathrm{X}_{1}\right)$ sebesar 0,411 menyatakan bahwa setiap kenaikan Penyalahgunaan Teknologi Informasi sebesar 1 satuan maka Perilaku Kecurangan Akademik Mahasiswa Akuntansi sebagai Calon Akuntan akan meningkat sebesar 0,411 satuan. Nilai signifikan variabel Penyalahgunaan Teknologi Informasi lebih kecil dari 0,05 yaitu sebesar 0,000 . Untuk nilai koefisien determinasi $\left(\mathrm{r}^{2}\right)$ diperoleh hasil sebesar 0,242 yang artinya 24,2\% perilaku Kecurangan Akademik Mahasiswa Akuntansi sebagai Calon Akuntan (Y) dipengaruhi oleh variabel Penyalahgunaan Teknologi Informasi, sedangkan $75,8 \%$ dipengaruhi oleh variabel yang tidak dihitung dalam pengujian hipotesis ini. Nilai $T_{\text {hitung }}>t_{\text {tabel }}$ yaitu 3,470 $>2,03452$. Hal ini berarti Penyalahgunaan Teknologi Informasi berpengaruh positif terhadap Perilaku Kecurangan Akademik Mahasiswa Akuntansi sebagai calon Akuntan.

Hasil penelitian ini sejalan dengan penelitian yang dilakukan oleh Herman Purwono (2014) yang menemukan bahwa penggunaan Handphone Berpengaruh Terhadap Mencontek. Oleh sebab itu, teknologi informasi merupakan salah satu bidang ilmu yang perkembangannya semakin pesat dari tahun ke tahun. Ketika teknologi informasi semakin banyak dimamfaatkan dalam berbagai hal, banyak pihak-pihak dengan sengaja menyalahgunakan teknologi tersebut dengan cara mempergunakan sebagai alat untuk melakukan tidakan kecurngan.

Pengaruh Integritas Mahasiswa Terhadap Perilaku Kecurangan Akademik Mahasiwa Akuntansi sebagai Calon Akuntan.

Hasil uji hipotesis kedua menggunakan SPSS v.21 diketahui bahwa nilai koefisien Integritas Mahasiswa sebesar -0,328 dengan tingkat signifikan sebesar $0,000(<0,05)$. Nilai negatif koefisien Integritas Mahasiswa malambangkan jika Integritas mahasiswa ditingkatkan satu satuan maka Kecurangan Akademik akan menurun sebesar $-0,328$ satu satuan. Hasil ini menunjukkan bahwa Integritas Mahasiswa berpengaruh negatif terhadap variabel Kecurangan Akademik. Hasil penelitian ini sejalan dengan penelitian yang dilakukan oleh Tri Maria Veronikha, (2013) yang menemukan bahwa ada pengaruh yang negatif dan signifikan antara moral jugdement maturity dengan perilaku menyontek siswa. Oleh sebab itu, Integritas Mahasiswa akan mempengaruhi Perilaku Kecurangan Akademik Mahasiswa Akuntansi sebagai calon akuntan, karena dengan adanya integritas mahasiswa yang tinggi diharapkan mampu menurungkan tingkat kecurangan, sehingga faktor Integritas Mahasiswa secara langsung mempenngaruhi Perilaku Kecurangan Akademik Mahasiswa Akuntansi sebagai Calon Auntan.

Pengaruh Penyalahgunaan Teknologi Informasi dan Integritas Mahasiswa terhadap Perilaku Kecurangan Akademik Mahasiswa Akuntansi sebagai Calon Akuntan.

Hasil uji pada hipotesis ketiga dengan menggunakan SPSS v.21 bahwa 
variabel Penyalahgunaan Tekologi Informasi dan Integritas Mahasiswa berpengaruh negative dan signifikan terhadap perilaku Kecurangan Akademik Mahasiswa Akuntansi sebagai Calon Akuntan.hal ini ditunjukkan dengan menunjukan bahwa nilai $\mathrm{F}$ hitung sebesar 21,583 dengan tingkat signifikan 0,000 $(<0,05)$. Hasil ini memberikan makna bahwa variabel Teknologi Informasi dan Integritas Mahasiswa secara bersama-sama (simultan) berpengaruh terhadap Kecurangan Akademik. Artinya bahwa variabel Teknologi Informasi dan Integritas Mahasiswa berpengaruh signifikan dalam proses kecurangan Akademik. Hasil penelitian ini sejalan dengan penelitian yang dilakukan oleh Herman Purwono (2014) yang menemukan bahwa penggunaan Handphone berpengaruh terhadap Perilaku Kecurangan Akademik dan penelitian yang dilakukan oleh Tri Maria Veronika (2013) yang menemukan bahwa ada pengaruh yang negatif dan signifikan antara moral jugdement maturity dengan perilaku menyontek siswa, serta penelitian yang dilakukan oleh Amalia Nur latif ( 2014) yang menemukan bahwa terdapat pengaruh negatif dan signifikan efikasi diri terhadap kecurangan akademik.

\section{KESIMPULAN DAN SARAN}

\section{Kesimpulan}

Penyalahgunaan Teknologi Informasi berpengaruh positif terhadap Perilaku Kecurangan Akademik Mahasiswa Akuntansi Sebagai Calon Akuntan. Hal ini ditunjukkan dengan nilai Teknolgi Informasi sebesar 0,411. Nilai signifikansi variabel Penyalahgunaan Teknologi Informasi lebih kecil dari 0,05 yaitu sebesar 0,001 dan nilai $t_{\text {hitung }}>t_{\text {tabel }}$ yaitu $3,470>2,03452$. Hasil tersebut menunjukkan bahwa hipotesis pertama diterima.

Integritas Mahasiswa berpengaruh negatif terhadap Perilaku Kecurangan Akademik Mahasiswa Akuntansi Sebagai Calon Akuntan. Hal ini ditunjukkan dengan nilai Integritas mahasiswa sebesar -0,328. Nilai signifikansi variabel Integritas Mahasiswa lebih kecil dari 0,05 yaitu sebesar 0,000. dan nilai $t_{\text {hitung }}>t_{\text {tabel }}$ yaitu $-4,582>2,03452$. Hasil tersebut menunjukkan bahwa hipotesisi kedua diterima.

Penyalahgunaan Teknologi Informasi dan Integritas Mahasiswa berpengaruh terhadap Perilaku Kecurangan Akademik Mahasiswa Akuntansi Sebagai Calon Akuntan. Hal ini ditunjukkan bahwa dengan nilai $\mathrm{F}$ hitung sebesar 21,583 dengan tingkat signifikan lebih kecil dari 0,05 yaitu sebesar 0,000. Hasil ini memberikan makna bahwa variabel Teknologi Informasi dan Integritas Mahasiswa secara bersama-sama (simultan) berpengaruh terhadap Kecurangan Akademik. Artinya bahwa variabel Teknologi Informasi danIntegritas Mahasiswa berpengaruh signifikan dalam proses kecurangan Akademik.

Adapun faktor-faktor lain yang mempengaruhi variabel kecurangan akademik (Nursalam dan Munirah, 2013 : 137) anatara lain :

1. Individu, tujuan belajar dan tekanan orang tua

2. Lingkungan 
3. Situasional

4. Jumlah materi dan perceived be-havioral control

5. Organisasi dan situasi

6. Psikososial.

\section{Saran}

Berdasarkan kesimpulan hasil penelitian, dapat diberikan beberapa saran sebagai berikut :

1. Untuk masalah penyalahgunaan teknologi informasi sebaiknya pihak Universitas memperketat lagi pengawasannya, salah satu contohnya dengan mengumpulkan handphone pada saat ujian dan memastikan tidak ada mahasiswa yang menggunakan handphone saat ujian, serta memeriksa tugas dengan cermat agar tidak ada lagi mahasiswa yang hanya mengcopy paste tugas dari internet maupun dari teman.

2. Setiap mahasiswa harus berani mengungkap kecurangan yang dilakukan mahasiswa lain agar kecurangan tidak terjadi lagi.

3. Setiap mahasiswa harus mempunyai kesadaran untuk tidak melakukan kecurangan terutama pada saat ujian dan para dosen harus lebih memperhatikan semua mahasiswa pada saat ujian agar mahasiswa tidak mempunyai kesempatan untuk memberi jawaban kepada teman atau tidak saling memberi jawaban.

4. Penelitian selanjutnya diharapkan dapat menambah lagi jumlah variabel independen untuk penelitian dan memperluas lagi subjek penelitian.

\section{DAFTAR PUSTAKA}

Al. Haryono Jusuf. 2010. Auditing. Yokyakarta: STIE YKPN.

Dody Hartono. 2012. Bimbingan \& konseling Menyontek: Mengungkap akar Masalah dan Solusinya. Jakarta: Penerbit Indeks.

Gede Juni Wardana dan Edy Sanjaya. 2017. Pengaruh Motovasi Belajar, Integriras Mahasiswa dan Penyalahgunaan Teknologi Informasi. EJurnal S1 Ak. Universitas Pendidikan Genesha Singaraja. Vol : 8, No : 2

Jamal Ma'mur Asmani. 2010. Tips Efektif Pemanfaatan Teknologi Informasi dan Komunikasi dalam Dunia Pendidikan. Yogyakarta: DIVA Press.

Latip Diat Prasojo dan Riyanto. 2010. Teknologi Informasi Pendidikan. Yogyakarta: Penerbit Gava Media.

Nursalam, dan Munirah. 2103. Bentuk Kecurangan Akademik Mahasiswa PGMI Fakultas Tarbiyah dan Keguruan UIN Alauddin Makassar. Lentera Pendidikan Fakultas Tarbiyah dan Keguruan UIN Alauddin Makassar. Vol : 16, No : 2 
Nova Sarastini. 2013. http://bling jamong.wordpress.com/2013/11/18/11. Dampak dan Negatif Teknologi Informasi dan Komunikasi dalam bidang Pendidikan dan Ekonomi/. Diakses tangggal 10 Januari 2019

Purnamasari Dian. 2013. Analisis Pengruh Dime nsi Fraud Triangle Terhadap perilaku Kecuramgam Akademik Mahasiswa pada saat Ujian dan Pencegahannya. Jurnal Ilmiah Mahasiswa Fakultas Ekonomi dan Bisnis. Universitas Bramjaya, Vol : 2, No : 2

Sugiyono. 2017. Metodologi Penelitian Pendidikan Pendekatan Kuantitatif Kualitatif dan R\&d. Bandung : CVAlfabeta.

Tri Maria Veronikha K, dkk. 2013. Hubungan Moral Judgement Maturity dengan Perilaku Menyontek pada Siswa Kelas X SMA Negeri 8 Surakarta. Jurnal. Universitas Sebelas Maret.

Uma Sekarang. 2017. Metode Penelitian untuk Bisnis Pendekatan pengembangan Keahlian., Jakarta Selatan. Salemba empat

Wibisono. 2013. http://huntercommunity44.blogspot.com/2013/12/penyalahgunaan-teknologi-informasi dan.html. Diakses tanggal 10 Januari 2015. 